\title{
Una autobiografía psicoanalítica ${ }^{1,2}$
}

\section{Sandra Buechler 3}

Reflexiones Psicoanalíticas: Formación y Práctica (2017) es de alguna forma, una autobiografía. Es una crónica de mi propia trayectoria profesional. En él, repaso mis 19 trabajos y presentaciones entre 1988 y 2015, y reflexiono sobre cómo cada uno ha jugado un papel en mi propio desarrollo. El libro está dividido entre los trabajos sobre el tratamiento y aquellos relativos a la formación psicoanalítica, así como se ha dividido mi enfoque, de forma similar, a lo largo de toda mi vida profesional.

El libro comienza con el comentario de Soren Kierkegard de que la vida solo se puede comprender mirando hacia atrás, mientras hay que vivirla mirando hacia delante. Finaliza con unas líneas del poema de Cavafis "Ítaca". Os animaría a cada uno de nosotros a recordar nuestras propias Ítacas. ¿Qué es lo que nos dispone en nuestro viaje clínico y teórico? ¿Cómo lo vemos hoy de forma diferente a cómo lo veíamos al comienzo? ¿Qué hay que sólo se podría comprender en retrospectiva?

El leitmotiv es el tema de cómo cada uno de nosotros forma un estilo profesional. Mi descripción favorita es que estamos constantemente realizando audiciones a los posibles miembros de nuestro coro interno. Cada miembro de ese coro es alguien que ha tenido impacto sobre nuestra forma de trabajar. Profesores, analistas, supervisores, pacientes, amigos, colegas, miembros de la familia, pueden dejar huella sobre quién somos cuando estamos trabajando. Artistas, autores, compositores, y otros también pueden tener su papel. Mis poetas favoritos sin duda han afectado mi práctica clínica, como vais a escuchar. Cualquiera que nos diga algo sobre la condición humana puede formar parte del coro, y desde ese momento, sostenernos. Para mí, ciertos miembros, como mi primer supervisor analítico, mis analistas, así como los trabajos de Sullivan y Fromm, son solistas. Los busco cuando me

\footnotetext{
${ }^{1}$ Texto leído por Sandra Buechler en la segunda parte del Seminario Clínico en Ágora Relacional, 6 de Octubre de 2018. Traducción castellana de María Hernández Gázquez.

${ }^{2}$ Referencia para cita: Buechler, S. (2019). Una autobiografía psicoanalítica. Clínica e Investigación Relacional, 13 (1): 44-64. [ISSN 1988-2939] [Recuperado de www.ceir.info ] DOI: 10.21110/19882939.2019.130104

${ }_{3}^{3}$ Sandra Buechler, Ph.D. (New York) es Analista Didacta y Supervisora en el William Alanson White Institute. Supervisora en el Programa postdoctoral y de Residentes del Columbia Presbyterian Hospital, así como en el Institute for Contemporary Psychotherapy. Entre sus obras: Valores de la Clínica: Emociones que guían el tratamiento psicoanalítico (2004, 2018); Marcando la diferencia en la vida de los pacientes: Experiencia emocional en el contexto terapéutico (2008, 2015); Permanezco ejerciendo: Las alegrías y angustías de una carrera clínica (2012); Comprendiendo y tratando pacientes en Psicoanálisis Clínico: Lecciones desde la Literatura (2015) y Reflexiones psicoanalíticas. Formación y práctica (2018).
} 
siento pérdida. Cada momento de cada sesión ofrece tantísimas elecciones, la mayoría a un nivel por debajo de la conciencia. ¿Qué es lo que nos guía para centrarnos sobre A y no B? ¿Responderle? ¿Recordarlo y referirnos a ello en siguientes sesiones? ¿Qué hace que sigamos adelante, hora tras hora, día tras día, a pesar de confrontar con nuestros pacientes cada una de las penas conocidas por el ser humano? ¿Y cada terror, y todos los elementos de la vida más vergonzosos, culposos, furiosos, repugnantes y potencialmente deprimentes? Para cada uno de nosotros, ¿qué puede fortalecernos, para poder abrir la puerta el lunes a las 9 de la mañana sin saber si alguien que habita en nuestra propia pesadilla más terrorífica puede estar pidiendo nuestra ayuda?

Este es mi quinto libro, y con el beneficio de la retrospectiva, ahora puedo ver cómo continua a los demás. En mi primer libro publicado en 2004, estudié los valores clínicos tales como la valentía, el sentido del propósito y la esperanza, los cuales creo que juegan papeles clave para ambos participantes en el tratamiento. En el siguiente (2008) intenté aislar los aspectos cognitivo, emocional y relacional de la practica analítica. Claro que realmente no se pueden aislar unos de otros, pero los considero de forma separada para poder hablar de cómo podemos ayudar a los candidatos a desarrollar la habilidad de "Marcar una diferencia en la vida de los pacientes". En ese segundo libro también elaboro sobre el papel de algunas de las emociones clave en el tratamiento, incluyendo la alegría, la pena, la ira, soledad, vergüenza y otros. Me parecía natural que en mi siguiente libro estudiase las etapas en la carrera de un clínico. Cómo navegamos con los problemas que surgen en la formación, las ansiedades y nuestras primeras experiencias clínicas, las dificultades en la fase intermedia, y los retos bastante severos que pueden acompañar la finalización de la práctica. En ese libro (2012) titulado "Todavía ejerciendo", sugiero que las penas acumuladas debido a las repetidas pérdidas de pacientes y las experiencias acumuladas de insuficiencia, pueden sumarse. En el siguiente libro (2015), refino mi comprensión del proceso del tratamiento para adaptarlo a temas específicos del carácter de cada paciente. Estoy buscando una forma juguetona de estudiar los temas del carácter, y queriendo evitar las dificultades inherentes al uso del material clínico, elijo escribir sobre personajes en historias cortas, que ilustran los dilemas básicos humanos y los distintos estilos para sobrellevarlos.

Es en ese momento que IPBooks me ofreció publicar una colección de mis trabajos, junto con un comentario desde mi perspectiva actual. Intuitivamente pensé que, así como la secuencia de mis libros tienen sentido para mí, en retrospectiva, también podía ser cierto para estos trabajos. Es decir, que las bases de todos mis escritos es la creencia de que hay ciertos valores inmiscuidos en nuestro trabajo, y unas emociones experimentadas universalmente. Debido a estos valores y emociones compartidas los clínicos comprendemos tan frecuentemente los dilemas de otros analistas, requiriéndose pocas explicaciones. Cada uno 
de nosotros nos hemos enfrentado a pacientes con depresión seria, y convivido con la ansiedad de que cometan suicidio. Nos hemos enfrentado a la tragedia de vidas insatisfechas, vidas truncadas, personas sufriendo de extrema soledad, personas sin esperanza. Cuando un clínico habla con tristeza de llegar a casa del trabajo, y querer un periodo de silencio antes de comenzar a conversar, o llegar a la oficina por la mañana y sentirse diferente respecto del día dependiendo de los pacientes que estén en la agenda, o ser incapaz, por el momento, de dejar atrás la última sesión para entrar en la siguiente, lo entendemos. Hemos estado ahí, lo hemos vivido.

Mientras nuestras experiencias pueden distar unas de otras de muchas maneras, hay también un común denominador. Creo que nuestros valores, nuestras emociones, la experiencia acumulada en las diferentes fases de nuestras carreras, y nuestras luchas con el reto fundamental del ser humano, nos pueden conectar. En las conferencias hablamos mayormente de nuestras teorías y de otras diferencias. Discutimos sobre qué patrón es más útil en la clínica, o más certero de alguna forma. Pero creo que tenemos mucho más en común que las diferencias que podemos tener, si sólo tuviéramos la voluntad de verlo. Como tantas veces lo es para mí, nuestro reto central está articulado claramente por el poeta Rilke.

Rilke dice, "...Y es que, en realidad, sobre todo ante las cosas más hondas y más importantes, nos hallamos en medio de una soledad sin nombre. Para poder aconsejar y, más aun, para poder ayudar a otro ser, deben ocurrir y lograrse muchas cosas. Y para que se llegue a acertar una sola vez, debe darse toda una constelación de circunstancias propicias." (Rilke, R.M. (1934) Cartas a un joven poeta. Libros en Red.com. p. 10, en Buechler, 2018 "Reflexiones Psicoanalíticas, p. Ix) 1.

Puesto que todos comenzamos con nuestra formación, empezaré observando algunos hilos conductores de esa primera mitad del libro. Aquí empecé a jugar con la idea de que aportaba mis primeras experiencias en los hospitales, a mi formación analítica, y de forma más amplia que aportaba todo lo que había llegado a conocer. Al menos en mi primera formación, me parecía que se presuponía que entrábamos como páginas en blanco. Pero claro, esto no es así. Al escribir un trabajo poco después de graduarme, descubrí en mí una apasionante necesidad de conectar los peores años que pasé con pacientes de hospital de día, con el trabajo que estaba realizando. Esta necesidad de encontrar una utilidad para todo lo que había conocido, me atrajo a los escritos de Erich Fromm. Encontré en él el intenso compromiso que yo ansiaba. Mirar hacia atrás a aquellos primeros trabajos, clarificó su influencia.

Considero que Fromm informa todos los trabajos de esta sección. En el primero, "Uniéndome a la cultura psicoanalítica", Fromm está en el trasfondo, alentándome hacia mi 
propia realización. Su frase, "... como tengo ojos necesito ver, como tengo oídos necesito oír, como tengo cerebro necesito pensar y como tengo corazón necesito sentir." (Fromm, 1968, p.72) me inspira para luchar por usar todos mis recursos completamente, y para que los candidatos utilicen los suyos completamente. En este trabajo de mis primeros tiempos, estaba buscando la voz que utilizara mis fortalezas personales y también honrara a mis antecesores (Buechler, 2018, "Reflexiones Psicoanalíticas" p.4).

Ahora puedo ver que siempre he estado en conflicto entre buscar la aprobación y querer desarrollar una voz independiente. Esto se manifestaba de muchas maneras, y creo que hizo que me fuera más difícil saber dónde me situaba yo. Pero incluso en esa época temprana intuía que, al menos para mí, la formación era un proceso de aculturación.

"En este trabajo me gustaría tratar la profesión del psicoanálisis como si fuera una cultura. No nacimos en esta cultura, pero hemos elegido entrar en ella. Durante nuestro periodo inicial de aculturación, debemos aprender su lenguaje, sus códigos morales, su ética de comportamiento. Nos adaptamos a sus adversidades y encontramos formas de disfrutar de las gratificaciones que ofrece. Dependiendo de nuestro talento, personalidad, e historial experiencial elaboramos nuestros distintos roles en esta cultura. Algunos de nosotros nos convertimos en líderes, quizás incluso héroes o heroínas, aventurándonos mas allá de las fronteras intelectuales de este campo, o desarrollando actividades políticas. La mayoría están contentos de trabajar este ámbito, por así decirlo, principalmente aplicando las formulaciones de otros. Nuestra cultura tiene forajidos, renegados que violan las reglas escritas y no escritas. Nuestro lenguaje tiene muchos dialectos, algunos tan pretenciosos y oscuros que pueden resultar difíciles de seguir, incluso para los miembros de los grupos vecinos. Tenemos nuestras tendencias y modas, y aquellos que intentan capitalizar su glamour. Tenemos nuestros tradicionalistas, mantenedores de la fe, que nos recuerdan la riqueza en las escrituras de nuestros antepasados. Las costumbres pueden variar de grupo en grupo, aunque puede que seamos todos más iguales que distintos, si se nos observa desde un punto de vista que esté fuera de toda esta cultura." (Buechler, 2018 "Reflexiones Psicoanalíticas", p. 6).

Reconozco que mi experiencia durante la formación en alguna medida recapituló mi adolescencia. En ambas fui impaciente. Casi no podía esperar para tener señales de aceptación. Era bastante consciente de esto, e intentaba utilizar palabras sabias para atemperarme. Por ejemplo, leí y re-leí el requerimiento de Rilke de,

Deja a tus opiniones su propio desarrollo callado e inalterado, el cual, como todo progreso, debe venir desde lo más profundo y no puede ser forzado ni acelerado por 
nada. Todo es gestación y después sacar a luz (Rilke, p. 29 en Buechler, 2018 "Reflexiones Psicoanalíticas, p. 15).

Otro interés de toda la vida que nació en mis primeras experiencias es el papel de la vergüenza en cada momento en la carrera del clínico. Mi propio sentido de insuficiencia se alimentaba por (impacientemente) asumir trabajos para los que apenas estaba cualificada. Fuí líder de equipo no-médico en mi primer trabajo profesional, para un hospital del estado, cuando estaba aun entrando en la veintena. Así como había me había ocurrido en experiencias anteriores en hospitales de $V_{\text {eteranos }}^{2}$, el trabajo me resultaba intrigante, desbordante, y al borde de lo insoportable. Tuve tantos momentos de los que luego llamé "ansiedad con vergüenza", algo similar a la frase de Samuel Beckett, "No puedo seguir. Seguiré." Puedo mirar atrás a algunos de mis primeros escritos y verlos como un ruego a mis profesores, supervisores y otros, de no exacerbar la vergüenza que ya sentía. Bajo este prisma, comprendo mi profunda gratitud a Ralph Crowley33.

Muchos años después de mi graduación escribí una carta a Ralph. Como estaba muerto, no era una carta en el sentido habitual. Pero era el producto de mi esfuerzo por realmente entender lo que había hecho por mí. Publiqué esa carta en el libro. Me gustaría leer fragmentos, ya que creo que captura parte de lo que estaba buscando en mi formación y más allá.

"Tu forma de estar conmigo era consonante con los valores que estabas enseñando. Aprendí algo de cómo estar con mi paciente de cómo tú eras conmigo. De alguna forma equilibraste la curiosidad con la paciencia. Para mí, entonces, la curiosidad era una fuerza motora que anulaba la paciencia. Aun hoy algunas veces funciona así. La paciencia no es una de mis virtudes. Pero tú me la enseñaste, en cómo contrastabas conmigo. Contigo, por primera vez, fui consciente del poder que tienen los contrastes en la enseñanza.

Mi paciente parecía estar al borde del desastre. Ella vino a mí, posicionada entre el funcionamiento y el darse por vencida. Demandaba que la mantuviera a flote, $y$, en retrospectiva, puedo ver que demandé lo mismo de ti. Yo necesitaba creer que tú (de forma mágica) podrías darme las palabras que mantendrían el análisis el tiempo suficiente para que cuajara. Yo quería, que el paciente y yo tuviéramos una oportunidad. Solo darnos una oportunidad. Trabajaré duro. Lo prometo. Sólo dame una oportunidad al principio.

Sentí que tu veías más allá del principio, cuando yo aún estaba embrollada en él. Tú me recordabas a uno de mis primeros profesores, que me enseñó a conducir un coche y me decía que no sólo mirara en frente del coche, sino "más allá, a lo ancho y lo alto." 
Aun en esos primeros días reconocí que ese consejo se podía aplicar a algo más que la conducción de coches.

No eras llamativo. Otros deslumbraban con su aguda inteligencia y afilado ingenio. Y, lo reconozco, a veces me deslumbraban. Como tantos jóvenes, confundía inteligencia con sabiduría. Estaba impresionada por el ingenio afilado. Asumí que, si no lograbas ayudarme clínicamente, el fracaso era mío. Como tantos otros, estaba tentada a infravalorarte, porque tu no alardeabas. No estabas intentando ser impresionante. Estabas intentando ser Ralph.

Pasó el tiempo, y el tratamiento se afianzó, y, con muchas dudas, me mantuve en la formación. Fue una decisión dura. Me atraía la idea de volver a lo académico. Pero prevaleció mi deseo de forjar un instrumento clínico adecuado. En cierta forma, prevaleciste tú. Ahora puedo ver que lo que no ocurrió contigo fue tan importante como lo que sí. No me forzaste a elegir entre tú y lo que yo creía que era lo clínicamente correcto. $Y$ no es que nunca tuviéramos diferencias de opinión. Pero tu dejabas que la diferencia se quedara flotando en el aire. Parecías creer que era suficiente. Y lo era.

No parecía horrorizarte mi pasión. De hecho, no parecías creer que pudiera desacreditarme. Pensaba que para ser analista tendría que amansarme, y ocultarme bajo el abrigo de un barniz de "neutralidad". Me ayudaste a sentir que este aspecto de mí misma era algo útil, en lugar de ser algo a reprimir." (Buechler, 2018, "Psychoanalytic reflections", pp. 43-44).

En la carta luchaba por encontrar palabras para lo que Ralph me había enseñado. Este es el final de la misma.

"Tú lo hiciste diferente para mí, Ralph, al ser una parte fiable de mí. Con tu sagacidad, tu creencia en el potencial humano, y una integridad absoluta, siempre tendrás un papel significativo en mi coro interno. Como lo ha hecho en el pasado, tu voz continuará guiándome y dándome fuerza. Cuantas veces he recordado el momento en que te dije que me preocupaba que mi paciente quería utilizar el tratamiento para lograr ser lo suficientemente perfecta como para ir al cielo, y tú con tu habitual agudeza seca equilibraste mi seriedad diciendo, "Creo que deberías hacerle saber que no eres experta en eso". Tú me ayudaste a poner el tratamiento, al paciente y a mí misma en una perspectiva más amplia. Aparte de tu sagacidad y tu paciencia, profundamente aprecio tu entusiasmo por enseñar. Incluso parecía que lo disfrutabas, y no solo lo tolerabas. Tu actitud era contagiosa. Ahora, yo también lo amo. 
Sobre todo, espero que hayas entendido que me ayudaste al creer en mi antes de que yo pudiera hacerlo. Tu extrapolaste de quien yo era, a quien yo podía ser. Espero que supieras que serías una piedra angular el resto de mi carrera, el resto de mi vida.

Con amor, Sandra" (Buechler, 2018, "Psychoanalytic reflections", pp.47-48)

Por el camino, pensé sobre como entendía la empatía. Eso me llevó a definir una diferencia crucial para mí, entre lo interpersonal y otros puntos de vista. Brevemente, tiendo a dar menos crédito a lo que normalmente se denomina "proyección identificativa" que muchos otros. No quiero decir que no ocurra. Pero no creo que un paciente, ni nadie más, pueda "poner en mi" una experiencia para la cual no esté ya predispuesta. Traigo toda la experiencia de mi vida a cada momento en una sesión. En particular, traigo toda mi historia de cada emoción. Cada forma en que he vivido la ira, el miedo, la curiosidad, la alegría, el amor, la soledad, la vergüenza, la culpa, la ansiedad, la sorpresa y otras emociones, da forma a mis percepciones, mis recuerdos, mis respuestas. Creo que tengo que utilizar mis propios recursos emocionales, para ser de ayuda. Simplemente no siento que se pone algo en mí. Es posible que el proceso empático comience ahí, pero entonces necesito poder utilizar, a mis propios recursos emocionales para encontrar la resiliencia en mí y ayudar a fomentarlo en el otro. Así es como los describí en una charla sobre los inicios del desarrollo de la práctica (psicoanalítica).

"Quizás hayamos sentido una rabia, o ansiedad, o pena intensa y contagiosa en una sesión. Estar disponible para esta experiencia mutua es la primera etapa de la empatía curativa, pero, a mi entender por sí sola no es suficiente. La empatía curativa nos requiere apelar a todos nuestros recursos emocionales, para regresar a una contención curiosa. Una vez que hayamos hecho esto, nos podemos preguntar sobre todo el viaje, y esperamos aprender algo sobre nosotros mismos y el paciente. A veces al vivir una pena insoportable podemos entender mejor las pérdidas de nuestro paciente y la nuestra. Si el proceso se frena aquí, puede ser una simpatía reconfortante y por tanto aliviar la soledad en ambas personas. Mientras sin duda no es un mal resultado, a mi entender con frecuencia no es suficiente. Estoy de acuerdo con los conceptos del análisis como un proceso de cambio estructural, y no solo una mejoría de sentimientos dolorosos. Es decir, el objetivo del análisis es el cambio en el funcionamiento de la persona; como procesa sus experiencias, y no solo lo que son esas experiencias. En el análisis no es suficiente ayudar a las personas a sentirse mejor hoy. Nuestro objetivo es ayudarles a conocer la vida de forma diferente, de verlo de forma distinta. Para mi el cambio estructural significa oír con oídos nuevos, y ver con ojos nuevos. No solo ayudamos a las personas para oír o ver algo de forma más positiva hoy. Les ayudamos a oír y ver más vida, hoy y para siempre jamás. Ya no gastan un oído y un ojo intentando 
no oír y ver, es decir a la defensiva. Utilizan menos de sus recursos defendiéndose contra sus experiencias y más de sus recursos en vivir sus propias experiencias. Al soportar algo junto con el paciente sentimos como asimilan la vida. Y entonces utilizamos lo que tengamos dentro para recobrar la capacidad para el asombro y para conectar. $Y$ entonces ambos paramos, miramos hacia atrás, aprendemos y quizás cambiamos. Conectar empáticamente utiliza tremendos recursos emocionales. Se debe reclutar cada sentimiento positivo, de alegría a esperanza, a curiosidad y amor y es necesario tener la capacidad para soportar cada sentimiento negativo, desde la soledad a la ira, el miedo y la pena. Este trabajo nos requiere ser seres humanos que pueden pensar con sentimiento y sentir pensativamente. La formación debe sacar nuestro potencial natural para la relación empática". (Buechler, 2018, "Psychoanalytic reflections", pp.55-56).

Para mí, la persona que más se acercó a la definición de la complejidad de aprender a ser clínico, fue el poeta T.S. Eliot. Aquí hay unas breves líneas de "East Coker."

"Intentando aprender a usar palabras, y cada intento

Es un comienzo completamente nuevo, y un tipo distinto de fracaso

Pues uno solo ha aprendido a sacar lo mejor de las palabras

Para lo que uno ya no tiene que decir, o de la forma en la que

Uno ya no está dispuesto a decirlo. Y así cada intento es un nuevo comienzo, un ataque a lo no articulado

Con un equipo gastado siempre deteriorándose

En el desorden general de la imprecisión del sentimiento

Indisciplinados batallones de emoción".

(T. S. Eliot, Cuatro Cuartetos Trad. Jesús Placencia p. 7) (Buechler, 2018, "Psychoanalytic reflections", p. 6o).

Otro poeta, Edward Hirsh, también describió el reto de hacer significados juntos. El estaba hablando sobre la relación entre el poeta y el lector, pero su descripción me ha parecido muy adecuada para el proceso entre analista y paciente.

"Hacemos significados juntos, luchamos con lo que leemos y lo que le replicamos, nos hacemos más nosotros mismos en el proceso. Activamos el poema dentro de nosotros al comprometernos con él, lo más profundamente posible, al traerle nuestras vidas, nuestros recuerdos asociativos, nuestras historias pasadas, nuestros vocabularios, al dejar que su música verbal infiltre nuestros cuerpos, sus ideas penetren en nuestras mentes, al descubrir el patrón que emerge, al entrar en la cámara de los ecos que es la 
historia de la poesía, y sobre todo, al escuchar y prestar atención. (La atención es el rezo natural del alma. E. Hirsch, 1999 p. 260 cursivas añadidas en Buechler, 2018, "Psychoanalytic reflections", p. 294).

Otro hilo en mi escritura ha intentado capturar las fases de una carrera clínica. Desde el principio me convencí de que algunos de los retos siguen siendo los mismos, mientras otros cambian, a menudo de forma predecible. En resumen, ¿cómo soy clínico de forma distinta hoy? Y tu ¿cómo lo eres? Creo que los clínicos en las primeras etapas de nuestras carreras compartimos algunas ansiedades, y también algunas fortalezas. Y creo que ambas van menguando con el tiempo, aunque se pueden ir desarrollando otras fortalezas. He explorado los cambios a medida que los he ido sintiendo, en un trabajo llamado "Fuego en el Vientre."

Este trabajo habla sobre mi relación con la empresa clínica, desde un primer periodo de luna de miel, a través lo que pienso que son sus fases predecibles. Entre otras preguntas, se cuestiona qué es lo que puede conseguir mantener nuestro compromiso fuerte, cuando se desvanecen las iniciales ansiedades altamente motivantes? ¿Cómo podemos acicalar el fuego en el vientre? Aquí hay un vistazo sobre mí misma en los inicios, cuando la pura ansiedad animaba mi intenso compromiso.

"Una historia de mis primeros días, apasionados días. Enfrentada con uno de mis primeros pacientes infantiles en la clínica de asesoría juvenil donde trabajaba justo después de doctorarme, estaba desbordada, al no tener formación para trabajar con niños. Pero estaba determinada a agradar. La noche antes de la primera sesión "empollé". Es decir, me leí cuidadosamente el libro de Virginia Axline (1947) "Terapia de Juego", de cabo a rabo, memorizando partes del libro. Tras traer al niño de la sala de espera a mi oficina, articulé una versión de la fórmula de apertura de Axline. "Esta es tu habitación, tu tiempo, tus juguetes. Puedes jugar como quieras." La niña esperó pacientemente a que terminara mi discurso y entonces preguntó, "Y cuándo puedo hablar sobre mi problema?" Estaba tan ansiosa por hacerlo bien, por conseguirlo, que estaba priorizando hacerlo todo "bien" por encima de encontrar mi propio estilo y forma de relacionarme con el paciente. Tenía mucho que aprender. Para demostrar nuestra capacidad, especialmente al principio de nuestras carreras, creo que muchos intentamos demasiado ofrecer las respuestas "correctas" a las preguntas de nuestros pacientes, aunque, en algún nivel, sabemos que eso es imposible. En mi libro de 2012, "Todavía ejerciendo" (p. 109) desarrollo algunos de los efectos nocivos que esto puede tener sobre nosotros y nuestra relación con este ámbito.

Para anticipar comentarios que haré más adelante, diré que muy pronto en mi carrera estaba motivada a trabajar muy duro, en parte debido a la ansiedad. En otras palabras, 
para volver a la analogía con las relaciones, al principio estaba muy motivada para agradar. Pero más tarde en mi carrera, a medida que mi lugar si hiciese algo más seguro, ¿seguiría teniendo una motivación alta? $\mathrm{O}$, inevitablemente, ¿empezaría a tomar mi profesión por sentada, y dejaría de intentar hacer que la relación realmente funcionara? ¿Qué le pasaría al fuego en mi vientre?" (Buechler, 2018, "Psychoanalytic reflections", pp. 81-82).

Desde la mitad de mi carrera en adelante, diría que la necesidad de encontrar mi propia voz, y la confianza en los valores como el sentido del propósito, y las emociones, como la curiosidad y el amor, han sido lo que ha aportado la motivación.

Con mi enfoque en los valores y emociones que normalmente ocurren en los seres humanos, era inevitable que, a medida que empezaba mi trabajo con candidatos de otras partes del mundo, tuviera que confrontar el tema de cuánto debemos adaptar nuestra formación analítica a los antecedentes culturales del candidato. Ésta es una cuestión que me resulta muy compleja. Por ejemplo, cuando trabajé con varios candidatos japoneses, la mayoría de los cuales regresaban a Japón, ¿debía ayudarles a desarrollar un estilo que se adaptara más fácilmente a esa cultura? ¿O debería trabajar como siempre? Varios me dijeron que si era "polémica - confrontativa" como quiera que se defina, sería algo inaceptable de vuelta en sus casas. Ellos mismos sentían conflicto sobre lo que querían aprender, y sobre eso también tuve mis conflictos. Escribí un trabajo, incluido en este libro, intentando disertar sobre estos temas. Como siempre, intenté encontrar cosas comunes, así como reconocer las diferencias. En un libro llamado "Las geografías del psicoanálisis", en el que Preta me ayudó.

"¿...puede la hipótesis psicoanalítica tener un valor universal? ¿Pueden describir la misma-o-similar dinámica para cualquier humano, sin importar el contexto histórico, social y cultural?" (Buechler, 2018, "Psychoanalytic reflections", p.93).

Para mí, estas preguntas siguen mayormente sin respuesta.

Regresando a la práctica, encontré inspiración en la fuente habitual, en los poetas. Aquí las palabras de Rilke, tan infaliblemente sabias.

... Sólo alguien que está preparado para todo, que no descarta ninguna experiencia, ni la más incomprensible, vivirá su relación con otra persona como algo vivo y en si misma sondeará las profundidades de su propio ser." Rilke, R.M. (1934), Cartas a un joven poeta. Nueva York: Norton. (Buechler, 2018, "Psychoanalytic reflections"p. 104)

Mi primera incursión fue una discusión sobre lo que puede inspirar la esperanza activa, algo que veo como esencial para ambos participantes en el tratamiento. Digo "activo" porque me refiero a una pasión motivante, no solo la expectativa cognitiva de algo en el 
futuro. ¿Qué es lo que puede revolver esta pasión? Así es como lo veía en uno de mis primeros trabajos.

"Los aspectos de la esperanza activa que afirma un compromiso con la vida probablemente no se suele comunicar en el contenido de lo que se dice, sino más bien en el fervor del tono, en la fuerza de la convicción que se puede señalar por lo directo y la fuerza de lo hablado. En análisis, esto probablemente se transmite al paciente mediante unas actitudes personales y profesionales que el analista revela sin saberlo. Trabajo de amor, una pasión por promocionar la vida y el crecimiento, una postura empática hacia si misma y hacia los demás, una voluntad de luchar y la alegría en el humor y los retos de la vida, son algunos de los intangibles que se conocen en los sutiles tiempos y gestos de la música, más que en las palabras. En qué se centra el analista, a lo que responde, por lo que es capaz de romper el encuadre, lo que deja pasar en silencio, a lo que responde con pasión, lo que expresa en primera persona, por lo que se cansa, por lo que está dispuesto a luchar, dice mucho. Lo mismo se puede decir en la supervisión, donde las actitudes del supervisor y el supervisado sobre el tratamiento y la vida se estudian a menudo tanto explícita como implícitamente." (Buechler, 2018, "Psychoanalytic reflections" p. 116).

El siguiente trabajo pregunta ¿cuál es la "pasta correcta" para ser analista? Exploro el valor de la habilidad de prestar atención a las sutilezas en los cambios en cualquiera de las emociones, tanto en el analista como en el paciente. Freud escribió sobre la ansiedad-señal y Sullivan también priorizó la atención a los cambios en el nivel de ansiedad del paciente. Desde luego estoy de acuerdo, pero ampliaría esto para incluir el prestar atención a un cambio en mi propio nivel de curiosidad, como ejemplo. ¿Qué acaba de ocurrir antes de este cambio? Aquí mi muy esperanzada conclusión.

"Como el director que oye cada nota individual, el analista debe sintonizar con las sutilezas de los cambios mayores y menores en sí misma y en su paciente. El análisis requiere de nuestra presencia entera como personas humanas con auto-conocimiento y responsividad. El analista completamente apasionado puede sostener la fuerza y el coraje que se requiere para que de forma persuasiva llame a su paciente a la vida. (Buechler, 2018, "Psychoanalytic reflections" p.131).

Lo que sigue es un periodo en el que me centré principalmente en las emociones dolorosas que encontraba en mi trabajo. Me refiero a Fromm-Reichmann, y otros, que diferenciaban la soledad de emociones más dolorosas que la soledad, un estado que se puede sentir como permanente, como cualquiera que hayamos conocido una adolescencia en soledad o cualquier adolescente solitario puede atestiguar. En este trabajo empecé a ver 
cómo las formas predominantes del paciente por salir adelante, impactan la soledad del analista. Con cualquiera, puede que sintamos que tenemos que mantener algunas de nuestras respuestas "almacenadas", como Winnicott famosamente sugirió en su trabajo sobre el odio en la contratransferencia. Los sentimientos de soledad pueden acompañar a este sentido. Y llamo al "coro interno" para ayudar a sostenerme.

"El coro interno que traemos a nuestros despachos, cada día, debe ser de confort, y debe ser suficientemente estimulante, para animar al uso creativo de la soledad. La emoción que el coro debe darnos es que pase lo que pase hoy con este paciente en particular, no nos define como analistas, ya que ya hemos sido definidos y nos definimos nosotros mismos, a través de nuestras identificaciones analíticas y en la formación de la identidad. No estamos personal y profesionalmente en tela de juicio con cada nueva interacción con un paciente. Sobre esta base, podemos experimentar la soledad con un paciente como información, y no como un juicio. Podemos darle vueltas a la soledad en nuestras mentes, preguntarnos sobre qué es, ser curiosos sobre ello, verlo como algo significativo, como algo para comprender, no como un obstáculo o una acusación. Una soledad que no nos cueste una buena conexión con nosotros mismos, con nuestro coro, o con el paciente y que pueda ser utilizada creativamente. La soledad utilizada creativamente no es soledad.

Estar solo con el paciente no es doloroso, mientras podamos retener una conexión con nuestro buen sentido de nosotros mismos, y un sentido no-persecutorio del paciente. Los conceptos teóricos pueden ayudar a este proceso, ofreciendo algo con lo que jugar durante ratos de soledad con el paciente. Un buen coro interno que apoya y suficiente como para poder jugar puede, creo, permitir al analista posibilidades creativas para el uso productivo de la soledad." (Buechler, 2018, "Psychoanalytic reflections" pp. 158159).

Intentar definir lo que he llamado "neutralidad pasional" empezó a ser significativo para mí. Encontrar una forma de incorporar mi intensidad emocional a una postura analítica no era un tema nuevo, pero lo exploré en mayor profundidad a finales de los go. Fromm fue un guía de gran ayuda. A medida que le leía, también, iba buscando una forma de integrar sus fieros sentimientos con la práctica analítica. Creo que ninguno de nosotros ha encontrado una forma de abordaje totalmente adecuada. He formulado una respuesta, pero desde entonces la he puesto en tela de juicio.

"El compromiso pasional en el tratamiento es una inversión genuina en la vida misma. Se comunica a través de la "música" del tratamiento, en el tono, forma, ser directo, la alianza con la verdad y la convicción sentida profundamente sobre el significado del 
trabajo. La pasión se siente; la neutralidad es hablada. Las palabras del analista invitan al paciente a expresar todo lo que hay en él, incluso las fuerzas más autodestructivas y sádicas. Aunque sin darle forma conscientemente, las formas del analista transmiten un compromiso duradero con la vida y el crecimiento." (Buechler, 2018, "Psychoanalytic reflections" p. 179).

Esta forma de abordar depende de la inversión del analista en ser relativamente nonarcisista. Creo que no podemos y no debemos intentar la no-inversión, pero podemos sostener como un ideal una inversión relativamente no-narcisista. Aquí está como he intentado formular esto.

"Uno espera que el analista experimentado ya sepa que es competente. No necesita un "éxito" con su paciente para demostrarse a sí mismo ni a nadie mas. Por tanto, desde un punto de vista narcisista no esta comprometido con si el paciente consigue hacerse una buena vida para si mismo, o tan siquiera si el paciente tiene vida o no. Pero desde un punto de vista humano esto no puede ser un tema indiferente". (Buechler, 2018, "Psychoanalytic reflections" p. 179).

Un evento me sacudió profundamente. Una paciente de larga duración murió estando en la treintena. Mis escritos empezaron a centrarse en la pérdida. Empecé a pensar en qué se parecía y no la pérdida de un paciente, a otras pérdidas. Empecé a ver cómo estas pérdidas me estaban afectando como ser humano y pensando en lo que sería perder a todos mis parejas de tratamiento a lo largo de mi carrera. No es accidental que haya un capítulo sobre el duelo en cada uno de mis libros. Es el tema que más me absorbe por muchas razones.

La paciente que murió había sufrido de múltiples incapacidades, pero no había indicación de que estuviera en peligro inminente. Aquí es lo que escribí sobre lo que esta experiencia fue para mí.

"Estábamos en lo que parecía ser una fase particularmente productiva del tratamiento. Por fin (desde mi punto de vista) el paciente estaba reconociendo aspectos narcisistas de su personalidad que le habían impedido que desarrollara una relación duradera. A sus treinta y cinco años sentí que por primera vez realmente estaba preparada para comprometerse con una intimidad mas profunda. Toda su vida había sido una lucha con coraje, en cada momento, contra la incapacidad física. Ahora parecía más preparada para emerger más completamente de las constricciones de sus limitaciones psicológicas. Fue durante el fin de semana que recibí el mensaje de que había muerto repentinamente. 
Mi experiencia de perder a esta paciente fue extremadamente dolorosa, pero se que no soy de lejos la única en haber soportado una pérdida semejante. ¿Cómo soportamos estas pérdidas? ¿Qué efectos tiene a lo largo del tiempo, sobre nuestras vidas personales y profesionales?" (Buechler, 2018, "Psychoanalytic reflections" p. 184).

Lo que llegué a sentir es que la pérdida de un paciente es única, en que realmente no tenemos a nadie que conociera al paciente con quien compartirla. Normalmente cuando perdemos a alguien, podemos hablar con aquellos que le conocían a él o ella. Podemos compartir recuerdos, lágrimas y quizás una triste sonrisa de reconocimiento. Sin embargo, la pérdida de un paciente nos deja particularmente, peculiarmente solos. No podía decirle a su familia o amigos lo que sabía sobre ellos, desde el punto de vista de mi paciente. No podía compartir con ellos mis recuerdos de nuestro trabajo juntos. Podía hablar con mis compañeros sobre la pérdida, pero no la conocían a ella. Los rituales que se supone que nos deben de ayudar con las pérdidas no me ayudaron con esta. Aquí está como lo describo.

"No tenemos rituales institucionalizados para manejar estas pérdidas. Es como si el hecho de que la persona es un "paciente" hiciera que fuera innecesario un ritual. Si muriera o se fuera de forma permanente un colega, amigo o pariente no esperaríamos que "siguiéramos" sin un duelo. Pero porque, en algún sentido fundamental, nuestro papel anima a la negación del impacto personal de nuestra relación con pacientes, también negamos el significado personal de su muerte o partida." (Buechler, 2018, "Psychoanalytic reflections" p. 192).

En este trabajo describo una gama de pérdidas que soportamos repetidamente. Mientras esperamos que la mayoría de nuestros pacientes no se mueran, sí que terminan, de alguna forma $u$ otra. Y hay muchas pérdidas sutiles de fe en este campo, y el respeto de una cultura más amplia, que se pueden acumular. Me preguntaba cómo podría soportar mejor este aspecto de mi trabajo. Aunque sea una respuesta limitada, aquí esta.

"La tristeza poco a poco limpia, y nos permite volver a la lucha. Y nos familiariza más con casi todo lo que es ser humano, nos ata unos a otros, y agudiza nuestra apreciación de los momentos de alegría. Nos da la perspectiva de las vicisitudes normales y extraordinarias de la vida. Como analista, es necesario que haya desarrollado una fuerte tolerancia a la pérdida y la tristeza, ya que siempre están próximos.

Doblo la esquina y "veo" al paciente que he mencionado anteriormente que murió hace años. Me doy cuenta de cuantas veces ha ocurrido esto a lo largo de los años desde que murió. Al principio pensé que sería un fenómeno pasajero, una fantasía de deseo expresada cuando echaba de menos su humor y valentía. Comprendo que estos momentos reflejan de forma significativa los aspectos personales de mi relación 
continua con la pérdida. Pero durante estos breves instantes ella está aquí de nuevo, y no solo viva sino bien, caminando, sin silla de ruedas. La fantasía me da una pausa momentánea del soportar la triste realidad. Y el dolor de su pérdida no es menor ahora que cuando murió y mis sentimientos de lamento de que no haya tenido más tiempo están inalterados. Lo que sí es diferente es que años de auto-reflexión me han clarificado algunos de los significados personales de su vida y muerte. Ahora traigo esta mayor claridad a cada instancia del duelo activo de su pérdida. Y la experiencia acumulada me han enseñado algo sobre lo mucho que ella ha contribuido a mi crecimiento personal y profesional. Cada momento actual clínico y anti-clínico que recuerdo, la experiencia de su iluminación incrementa mi apreciación por ella. Recordarla cada vez me ayuda en alguna forma, a equilibrar lo que he obtenido de ella versus los cambios sufridos. Sé ahora mucho más sobre lo qué me aportó, y me sigue aportando profesional y personalmente verla, y como me gustaría utilizar ese crecimiento. La tristeza está haciendo su trabajo esencial, al unirme más firmemente a la vida." (Buechler, 2018, "Psychoanalytic reflections" p. 198).

Mirando atrás, creo que nunca he perdido la teoría de la emoción que hay en mí. Trabajé con Carrol Izard, Robert Emde, y otros, en una beca NSF para estudiar las expresiones faciales de las emociones durante los dos primeros años de vida. Ese trabajo me convenció de que cada emoción que sentimos está afectada por todas las otras emociones que estamos experimentando. Así que, si estoy triste, pero también avergonzado, puedo tener menos fortaleza para soportar la tristeza que si estoy triste pero no particularmente avergonzado. Esta forma de pensar me ha sido de gran utilidad, tanto clínicamente como personalmente. Para mi significa que, por ejemplo, si alguien está deprimido, podemos centrarnos en todas las demás emociones que están presentes o ausentes, y no necesariamente en la depresión en sí, lo cual puede ser, en más de un sentido, un fondo de saco. Me interesé especialmente en la alegría, y las oportunidades para la alegría en el tratamiento, para ambos participantes. Cada uno de nosotros tenemos la oportunidad de celebrar los pasos hacia delante, los obstáculos que se sobrepasan, los crecimientos alcanzados. A esto lo llamo "alegría trascendente". Especulé que esos momentos de alegría son parte de lo que nos capacita para soportar las experiencias dolorosas en el tratamiento. Aquí está la conclusión a la que llegué.

"Puede haber alegría en reconocer nuestra común naturaleza humana, y puede haber alegría en apreciar nuestras diferencias. Las oportunidades para estas alegrías son abundantes en el proceso analítico. Por mi parte, a menudo he pensado en el análisis como un proceso que reta a ambos participantes para conocer estas alegrías suficientemente bien, como para soportar nuestras inevitables frustraciones, penas y otras erosiones del espíritu. 
Hace muchos años tome un curso en metáfora, esperando mejorar mi habilidad para escribir poesía. No creo que el curso haya conseguido este objetivo, pero si me dio unas herramientas conceptúales que he adoptado en mi trabajo analítico. El curso nos enseñó a ser capaces de "hacer lo extraño familiar, y lo familiar extraño." Nos dieron ejercicios y pedían, por ejemplo, que inventáramos una nueva forma para una bandeja de cubitos de hielo. ¿Cómo podíamos retener su esencia "cubitera" pero también cambiarla?

Algunas de las tareas del analista son similares. En las inicialmente raras, extrañas, inquietantes historias de vida que escuchamos debemos encontrar las señales familiares de la común humanidad. Pero, igual de a menudo, debemos notar lo extraño donde el paciente sólo ve lo que asume es universal. Un conocimiento mayor de lo profundamente humano y lo ricamente idiosincrático nos brinda algunas de las potenciales alegrías en la vida analítica." (Buechler, 2018, "Psychoanalytic reflections" pp. 212-213).

En varios de mis siguientes trabajos amplío mi búsqueda de una postura con suficiente neutralidad pasional. Exploro lo que ocurre cuando nuestro propio estilo defensivo es muy similar al del paciente. Mas especificamente, ¿qué ocurre si tanto el paciente como yo misma tendemos hacia la defensa esquizoide? Aqui hay otra oportunidad más para que nuestro coro interno entre en juego.

"Pero siento que cuando estoy en presencia de un paciente desconectado, impasible, esquizoide, puedo buscar activamente a la luchadora que hay en mi. Me puedo preguntar dónde está hoy. Puedo recordar sus anteriores batallas y sus resultados. Puedo pensar en aquellos que han luchado por la vida en mi presencia, y a veces, por mí. Puedo recordar momentos, incluyendo algunos con mis propios supervisores y analistas, que han comunicado su intensidad espiritual y determinacion por vivir cada momento, tanto en el tratamiento como fuera, al maximo". (Buechler, 2018, "Psychoanalytic reflections" p. 229).

Llegué a pensar sobre el papel del arrepentimiento en mi trabajo y las oportunidades para la reparación que me ofrece. Evoqué una de mis primeras experiencias, cuando un paciente de mi pabellon se suicidio, justo despues de haberme entrevistado con él, y mientras dirigía una reunion planificando el curso de su tratamiento. Por supuesto pensé en los signos de sus desesperacion que me pude haber perdido. Una vez más entré en contacto con mi impaciencia, y especulé sobre cómo su consistencia en mi naturaleza habia contribuido a la profundidad de mi arrepentimiento. Aquí está cómo lo entendí. 
"Lo que recuerdo es hacer una cosa detras de otra, centrándome en los detalles; los informes que se tenían que hacer, los papeleos de la muerte. Al final de mi turno me alejé del hospital en mi coche. Aparqué sin ningun plan consciente sobre qué hacer. Caminé toda la noche, atravesando pueblos, aparentemente concentrada en seguir en movimiento. En las muchas horas antes de la madrugada, antes de volver al aparcamiento y mi trabajo, me pregunté qué fue lo que no supe ver en la entrevista con James. Debieron haber pistas sobre su estado de animo desesperado. Un clínico con más experiencia los hubiera detectado, y hubiera podido prevenir la tragedia, de alguna forma. Quizas pude haber persuadido a James que tuviera esperanza, o al menos, haberle puesto vigilancia. No tenía que haber cogido este trabajo. No estaba preparada. ¿Por qué no lo supe? ¿Por qué no me tomé más tiempo, en lugar de darme por vencida al intentar llegar a él? ¿Era porque era hora de salir corriendo a la reunión de equipo? Era la hora de hablar sobre sus cuidados, asi que no tenia mas tiempo para hablar con él. Revisando estas instantáneas de mi misma, un día hace muchos años, reconocí el arrepentimiento entremezclado con la tristeza y la culpa. Mi arrepentimiento era por el peligro que no habia sabido reconocer. Mi tristeza era por una vida perdida. Mi culpa era por el egoismo de asumir un empleo porque lo necesitaba, no porque me sintiera realmente cualificada. Creo que la culpa y el arrepentimiento se mezclaban con el sentido de mi misma, corriendo para cumplir con las tareas del día, de tal forma que el haberme perdido las señales de la desesperación de James reflejaban, para mi, una verdad sobre mi caracter. Siempre tenía demasiada prisa. Acepté la falta de responsividad de James con demasiada facilidad, porque abreviaba una entrevista que haría que llegara en hora a mi siguiente reunión. Mi impaciencia se dejaba ver en la sesión con James, y más en general, en cómo conducía mi carrera. Subiendo, subiendo, esa soy yo. Pero, todavía me puedo preguntar, ¿a qué precio y quién, ademas de mí misma, han pagado por ello?" (Buechler, 2018, "Psychoanalytic reflections" pp. 242-243)

Para mí, fue útil explorar algunas de las raíces de las distintas actitudes sobre el soportar dolor. Esto se convirtió en un trabajo que preguntaba cómo las actitudes del clínico afectan el análisis de las defensas. Al pensar sobre esto me acordé de una experiencia que tuve en el postgrado.

"Cuando estaba en el postgrado, tuve un profesor el cual era muy admirado, tenía conocimiento teórico y era intelectualmente agudo. Podía debatir con cualquiera, en cualquier argot analítico. Tenía el listón muy alto y esperaba que sus estudiantes y pacientes dedicáramos muchos de nuestros recursos (tanto económicos como otros) en una búsqueda incesante de iluminación. Recuerdo pensar, "Este hombre no 
entiende lo dura que es la vida real." Miro hacia atrás sabiendo ahora que es posible amar la teoría y apreciar las durezas de la vida. Pero ¿acaso manifestamos esta apreciación completamente en nuestros métodos de trabajo y declaraciones públicas? ¿Acaso nuestras acciones, en sesión - es decir, lo que subrayamos y lo que ignoramos reflejan una comprensión compasiva de lo sobrepasadas en número, desbordadas, y poco preparadas se sienten las personas con tanta frecuencia cuando se enfrentan con enfermedades serias, padres deteriorándose, estrecheces económicas, niños vociferando, horarios solapados, prioridades encontradas, las dificultades de envejecer bien, junto con muchos otros quehaceres diarios? ¿Estamos de alguna forma fracasando en la transmisión de nuestra comprensión de estos temas? $\mathrm{O}$, como mi profesor de post-grado, ¿estamos algunos perdidos en las teorías que son atractivas intelectualmente pero no están suficientemente basadas en la vida tal y como se vive?

Es cierto, todos experimentamos sufrimiento, pero es posible que no hayamos formulado completamente nuestra actitud sobre su lugar en la vida psíquica. ¿Cuándo se debe de soportar el sufrimiento, en lugar de medicarlo, enmudecerlo o erradicarlo? ¿Cuándo ha de tomarse como señal de una apreciación total de la condición humana, y no como una señal de una patología? Nuestras actitudes sobre el sufrimiento tienen un efecto significativo en gran parte de nuestro comportamiento en una sesión, y más concretamente, sobre nuestra forma de abordar el análisis de las defensas. Puede ser de valor para nosotros reflejar sobre nuestras actitudes ante el sufrimiento, y sus orígenes personales, teóricos, religiosos y filosóficos, y su impacto en nuestra forma de abordar nuestro trabajo clínico." (Buechler, 2018, "Psychoanalytic reflections" pp. 254255).

Brevemente, sugiero que cuando vemos nuestro papel principalmente como el de facilitar la disminución del dolor, probablemente vamos a ser muy tolerantes hacia las defensas, las cuales, al menos al principio pueden verse como aliadas. Pero aquellos de nosotros que nos inclinamos a pensar que la forma en que las personas intentan evitar el dolor son temas problemáticos, es más probable que nos empleemos en el análisis de las defensas desde las etapas tempranas del tratamiento. Probablemente sobra decir que estas actitudes tienen profundas raíces personales, así como culturales y profesionales. Me encanta una declaración sobre el funcionamiento del dolor, de Lee Springer.

"Uno envejece y va sabiendo más a lo largo del tiempo; los encantos más fáciles de la vida se atenúan; las almas añoran, buscando más de lo que se puede tener en esta tierra, más de lo que se puede sonsacar de las tres dimensiones y cinco sentidos. Nosotros, todos nosotros, sufrimos en parte por los límitaciones de vivir dentro de la carne. Nuestro camino en este mundo nunca está completamente sin dolor. Acecha en las 
horas quietas y calladas las cuales evitamos insistentemente con nuestras constantes ocupaciones. Y se me ha ocurrido que quizás lo que llamamos depresión realmente no es un trastorno en absoluto, sino como un dolor físico, un tipo de alarma, que nos alerta de que algo sin duda está mal, y que quizás es el momento de parar y sacar tiempo, tomar el tiempo necesario para atender al asunto de llenar nuestras almas, a las cuales no nos hemos dirigido." (pp. 112-113). (Buechler, 2018, "Psychoanalytic reflections" p.275).

Recientemente regresé al postulado genial de Sullivan, de que todos somos simplemente más humanos que cualquier otra cosa, para preguntarme qué significa para mí, como persona y como clínico. Lo comparé con declaraciones que suenan similar, en el "Mercader de Venecia" de Shakespeare, y en "El Ahogado y el Salvado" de Primo Levi. No puedo resumir la voluminosa literatura sobre las declaraciones de Levi, pero encuentro que su esfuerzo por ver la humanidad en sus torturadores, es especialmente conmovedor.

"... nos preguntan los jóvenes quienes eran nuestros "torturadores", de qué pasta estaban hechos. El termino torturador alude a nuestros ex-guardianes, la SS, y en mi opinión es inapropiado: nos evoca individuos retorcidos, mal-nacidos, sádicos, afligidos por una falla original. Sin embargo, estaban hechos de la misma pasta que nosotros, eran seres humanos medios, con inteligencia media, maldad media: salvo excepciones no eran monstruos, tenían nuestras caras, pero habían sido criados mal. Y eran, en su mayoría, diligentes seguidores y funcionarios, algunos fanáticamente convencidos de la doctrina Nazi, y muchos indiferentes, o demasiado temerosos del castigo, o deseosos de una buena carrera, o demasiado obedientes (p. 202)". (Buechler, 2018, "Psychoanalytic reflections" pp. 296-297).

En un trabajo sobre "La mediana edad de Henry James y la mía propia" pensé sobre las fases mediana y posterior de mi carrera. En su historia corta "El comienzo de la Madurez" - o "La Edad Madura" ${ }^{4}$, James dice de Dencombe, un escritor que lucha por reconocer dónde se encuentra en su vida y su obra. Aquí está lo que dije sobre el significado personal para mí.

"Dencombe llora vividamente en duelo por las menguantes oportunidades. "Nunca más será, como lo fue en uno o dos grandes momentos del pasado, mejor que si mismo. Lo infinito de la vida se había ido, y lo que permanecía de la dosis era un pequeño vaso marcado como un termómetro por el boticario." Las lágrimas inundaban los ojos de Dencombe, al reflejar que para el, "... algo precioso había desaparecido. Este era el golpe de dolor que había sido el más agudo durante los últimos años - la sensación del desvanecimiento del tiempo, de la oportunidad encogiéndose; y ahora sentía no tanto que su última oportunidad estaba 
desapareciendo, sino que realmente ya había desparecido. Había hecho todo lo que jamás haría, y sin embargo no había hecho lo que quería". (p. 173).

Lo que me conmueve es que Dencombe, simultáneamente comprende lo que más quiere decir, y tiene la visión de que no tendrá el tiempo suficiente para decirlo. Paralelamente, la mediana edad ha sido para mi una época de una precipitante escalada de arrepentimientos. Caminos no tomados se están desvaneciendo rápidamente. Hay mundos que me hubiera gustado explorar, libros que hubiera querido escribir, y los "Sí mismos" que hubiera querido ser. Antes en mi vida escribía poesía, estudiaba historia del arte, investigaba sobre las expresiones faciales de las emociones, y trataba a niños psicóticos. Me prometí a mí misma que volvería a rescatar a esos "Sí mismos" inacabados del olvido, pero ahora creo que romperé todas esas promesas.

El duelo por los "Sí mismos" que una vez fuimos, y aquellos y nunca seremos, se puede convertir en un trabajo a tiempo completo. Puede que parezca una persona de camino a algún sitio, pero, como Dencombe, estoy agudamente consciente de los sueños que permanecerán sin cumplirse. Este trabajo está en la convergencia de las vidas profesionales y personales justo antes de extinguirse; "Sí mismos" que nunca tuvieron su oportunidad, y algunos que si. Esbozo mi perspectiva desde este punto de visión de "post-mediana edad" $y$ lo ofrezco a todos aquellos aun en etapas tempranas de sus carreras, así como a compañeros en las "edades medianas" y "más allá." (Buechler, 2018, "Psychoanalytic reflections" p. 301).

Pero a diferencia de Dencombe, quiero degustar completamente mis arrepentimientos, ya que están tan repletos de experiencia como cualquier otro. Y terminaré con una nota esperanzadora.

"Por último, mis años medianos me han dado una buena sensación sobre el futuro. No me refiero a mi propio futuro, sino, al futuro de nuestro campo. Sé que hay muchas razones para una preocupación real. Pero he conocido a muchos recién llegados al trabajo clínico ávidos. La forma de nuestra profesión puede cambiar. Pero siento gran confianza en la generación venidera. Siempre habrá una necesidad de personas que puedan atender a la fuerza de la vida. Y tengo fe de que siempre habrá personas con la voluntad de hacer ese su trabajo de vida." (Buechler, 2018, "Psychoanalytic reflections" p.305).

\section{Referencias de los libros publicados por Sandra Buechler, mencionados antes:}

Buechler, S. (2018). Valores de la Clínica. Emociones que guian el tratamiento psicoanalítico. Madrid: Ágora Relacional [v. Original: Clinical values: Emotions that guide psychoanalytic treatment. Hillsdale, NJ: The Analytic Press, 2004] 
Buechler, S. (2015). Marcando la diferencia en las vidas de los pacientes. Experiencia emocional en el ámbito terapéutico. Madrid: Ágora Relacional. [V. original: Making a difference in patients' lives. New York: Routledge, 200

Buechler, S. (2012). Still practicing. The heartaches and joys of a clinical career. New York: Routledge Buechler, S. (2015). Understanding and treating patients in Clinical Psychoanalysis. Lessons from literature. New York: Routledge

Buechler, S. (2018). Psychoanalytic Reflections. Training and Practice. IPBooks.

NOTAS:

${ }^{1} \mathrm{~N}$. de.T: traducción castellana ya publicada por librosenred.com

${ }^{2}$ N.de T.: Hospitales parea los miembros de las Fuerzas Armadas en EEUU.

${ }^{3} \mathrm{~N}$. de T: Su primer supervisor en la formación psicoanalítica.

${ }^{4} \mathrm{~N}$. de T. Son títulos de las ediciones en castellano, que sin embargo, estaría mejor traducido como "Los años de la mediana edad" 